\title{
COMPARATIVE ANALYSIS OF THE MANAGEMENT ACTIVITY TRAINING OF THE CADETS, STUDYING IN THE LOGISTIC SPECIALIZATIONS
}

\author{
Neno Hristov ${ }^{1^{\star}}$, Pavlin Glushkov ${ }^{2}$ \\ ${ }^{1}$ Colonel, Associate Professor, D.Sc. , National Military Akademy "G.S.Rakovski", Sofia, Bulgaria, \\ ${ }^{2}$ Major, Ph.D., National Military University, Veliko Tarnovo, Bulgaria, pavlin_glushkov@mail.bg \\ ${ }^{\star}$ Corresponding author
}

\begin{abstract}
The specific properties of the military professional activity of the Logistic officers are characterized by a high level of responsibility and taking of management decisions under limited time and material resources. They put forward definite requirements to the complete professional training of the future Logistic Officers and in particular to their management activity. In this connection the revealing of the possessed by the Cadets from the Logistic profile structural peculiarities of the management activity and management effectiveness appears to be an actual direction for the improvement of the military professional training and for the timely taking of high quality management decisions.

The target of research is the military professional training of the future Logistic Officers, while the subject of research is the training for management activity of the Cadets from the Logistic specializations.

The aim of the research is to reveal the state of the structural peculiarities of the management activity and of the management effectiveness of the future Logistic Officers.
\end{abstract}

Keywords: military professional activity, management activity, training the cadets

\section{INTRODUCTION}

The specific properties of the military professional activity of the Logistic officers are characterized by a high level of responsibility and taking of management decisions under limited time and material resources. Terziev and Nichev consider that they put forward definite requirements to the complete professional training of the future Logistic Officers and in particular to their management activity (Terziev and Nichev, 2017b, pp. 627-630) (Terziev and Nichev, 2017c, pp. 915-919) (Terziev and Nichev, 2017e, pp. 695-706). In this connection the revealing of the possessed by the Cadets from the Logistic profile structural peculiarities of the management activity and management effectiveness appears to be an actual direction for the improvement of the military professional training and for the timely taking of qualitative management decisions. 
During the clarifying of the connection aim-instrument-result it must be taken into consideration that the aim is a reflection in the form of an idea about a possible, future result of an action, on the achieving of which the efforts of a person are directed. It is a desired, expected and ideally foreseen result, towards which a person, group of people or a team deliberately move, forced by a definite motivation. The instrument is a way, means of acting, used to achieve a particular goal. It is a medium, means, manner, appliance or object, needed for the implementation of a definite activity, while the result is what appears at the end of some action, some process or event. It is a consequence of the persons' behavior (Nichev, 2017, pp 399-404) (Terziev and Nichev, 2017a, pp. 646-658).

\section{GENERAL LAYOUT OF THE RESEARCH}

The research work was carried out in the Land forces Faculty of the Vasil Levski National Military University during the period $2014-2016$.

The research comprises Cadets from the logistical specialties with specializations "Logistic troops and fuel and lubrication materials (FLM), "Movement and transport" and "Material resources, movement and transport".

The examined group consists of 42 people out of 42 , separated into the following subgroups (SG): SG1 - 16 Cadets, SG2 - 6 Cadets, SG3 - 20. The summarized data of the examined group are shown below in Table 1.

\begin{tabular}{|c|l|c|}
\hline $\begin{array}{c}\text { Sub- } \\
\text { group }\end{array}$ & \multicolumn{1}{|c|}{ Logistical specializations } & $\begin{array}{c}\text { Number of } \\
\text { trainees }\end{array}$ \\
\hline SG 1 & Logistic troops and FLM & 16 \\
\hline SG 2 & Movement and transport & 6 \\
\hline SG 3 & Material resources, movement and transport & 20 \\
\hline
\end{tabular}

Table 1 Summarized data of the examined group.

The research was carried out at three stages:

- first stage - examination of the literature and selection of the research methodology.

- second stage - conduct of the study. The empirical information was collected using the inquiry method in the format of a direct group questionnaire.

- third stage - analysis of the obtained results and drawing of conclusions.

\section{RESEARCH OF THE STRUCTURAL PECULIARITIES OF THE MANAGEMENT ACTIVITY}

The research of the structural peculiarities of the management activity is achieved through the methodology "Aim - instrument - result", elaborated by A. Karmanov. It's based on the connection of the management of the labor motivation between the set aim, the needed means and the expected result, reflecting the basic properties of each activity.

Each activity can be considered to comprise three components: at the beginning of each activity, the executor synthesizes a big amount of information and sets his own aims, meanwhile he begins to construct a definite idea of the desired end state of his activity; on a later stage the executor needs resources and means in order to achieve his goals; the end measurer of each activity is the obtained result - the benefit, implemented by the person (Malkina-Pykh,2005) (Terziev and Nichev, 2017a, pp. 646-658).

The methodology consists of a questionnaire with 32 questions, which comprise statements, connected with the character and the behavior of the examined person and processing of the answers by means of calculating and explanation of the results. According to the given legend the sum of the gathered points is determined. In Table 1 are presented the results of the carried out examination. 
IJASOS- International E-Journal of Advances in Social Sciences, Vol. IV, Issue 10, April 2018

Table 1: Components level from the methodology "Aim - instrument - result"

\begin{tabular}{|c|c|c|c|c|}
\hline Components and leves & Subgroup & SG 1 & $\begin{array}{c}G G \\
2\end{array}$ & $\begin{array}{c}S G \\
3\end{array}$ \\
\hline \multicolumn{5}{|l|}{ „Aim“component } \\
\hline Low level & & - & - & - \\
\hline Middle level & & 9 & 4 & 12 \\
\hline Optimal level & & 7 & 2 & 8 \\
\hline \multicolumn{5}{|l|}{ "Instrument" component } \\
\hline Low level & & - & 1 & 3 \\
\hline Middle level & & 11 & 4 & 11 \\
\hline Optimal level & & 4 & 1 & 4 \\
\hline High level & & 1 & - & 2 \\
\hline \multicolumn{5}{|l|}{ „Result“ component } \\
\hline Low level & & - & 1 & - \\
\hline Middle level & & 9 & 5 & 19 \\
\hline Optimal level & & - & - & 1 \\
\hline
\end{tabular}

The data from the conducted examination of the "Aim" component show, that:

- In their bigger part (59\%), the set by the Cadets aims are not well-grounded and are not stabile. Not all of the actions are reasonable and sometimes they are poor in content. They are amenable to taking of decisions influenced by external pressure. They need strong will, in order to prepare for the execution of a given activity.

- Within the examined group of persons, there are no such persons, who are not able to set constructive, well formulated and achievable goals.

- $41 \%$ of the examined group demonstrate an optimal result. They set themselves real goals, they are prepared to achieve them, their motives are purposeful and their activity is systematic and priority-arranged.

The data from the examination of the "Aim" component within the Logistic specializations are shown on Diagram 1.

Diagram 1: Summarized results of the "Aim" component

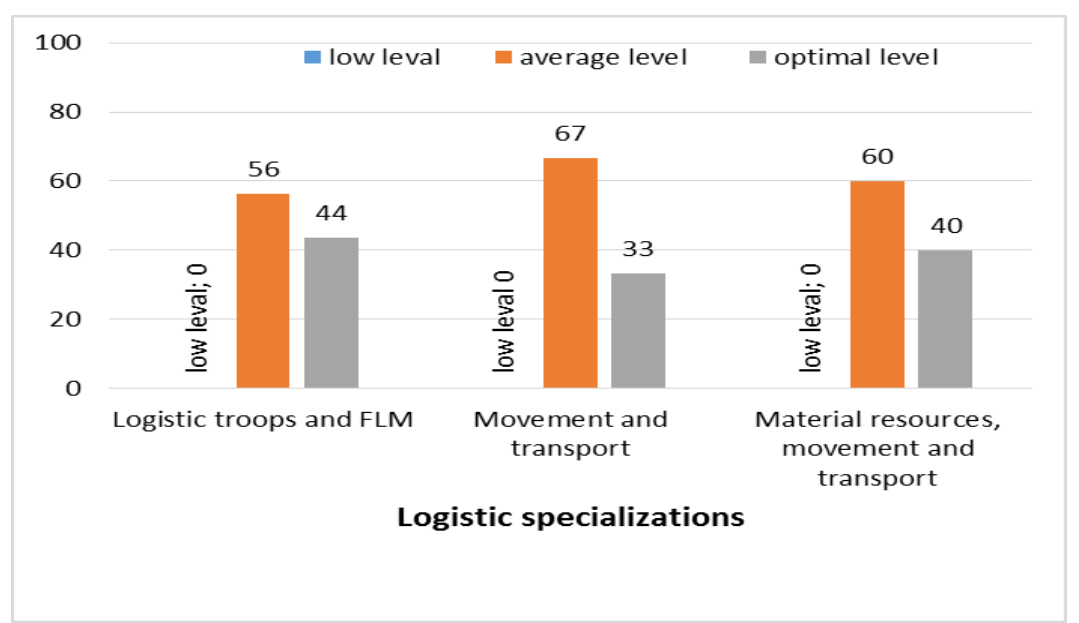

The data from the conducted research of the "Instrument" component demonstrate that:

- 9,5\% of the examined persons possess a low demonstration level. They experience a lack of means for achieving the set goals. Their typical displays are: the low potential possessed energy, strong dependency on the situation, strong dependency on other people, strong dependency on the opinion of the surrounding persons, presence of complexes, which hinder the complete use of the inner personal potential.

- 61,9\%of the examined Cadets have demonstrated a middle level. Sometimes they meet difficulties during 
their choice of means of achieving their goals.

- $21,5 \%$ of the future non-combatant officers show an optimal result. They feel free on choosing the means; their behavior depends on the requirements of the situation. An adequate potential energy is present and there is no change in their behavior or convictions in result of group pressure. Their behavior never induces complexes, distrust or negative thoughts.

$-7,1 \%$ of the examined demonstrate a high level, and their behavior is too spontaneous. They don't ask the other members of the team for help and prefer to be at the head of people and situations. Their actions have no respect for the existing standards of behavior, what often acts against them. An increased aggressiveness is present, which takes different direct and indirect shapes.

The data from the research of the "Instrument" component in the Logistic specializations are shown on Diagram 2.

Diagram 2: Summarized results of the "Instrument" component

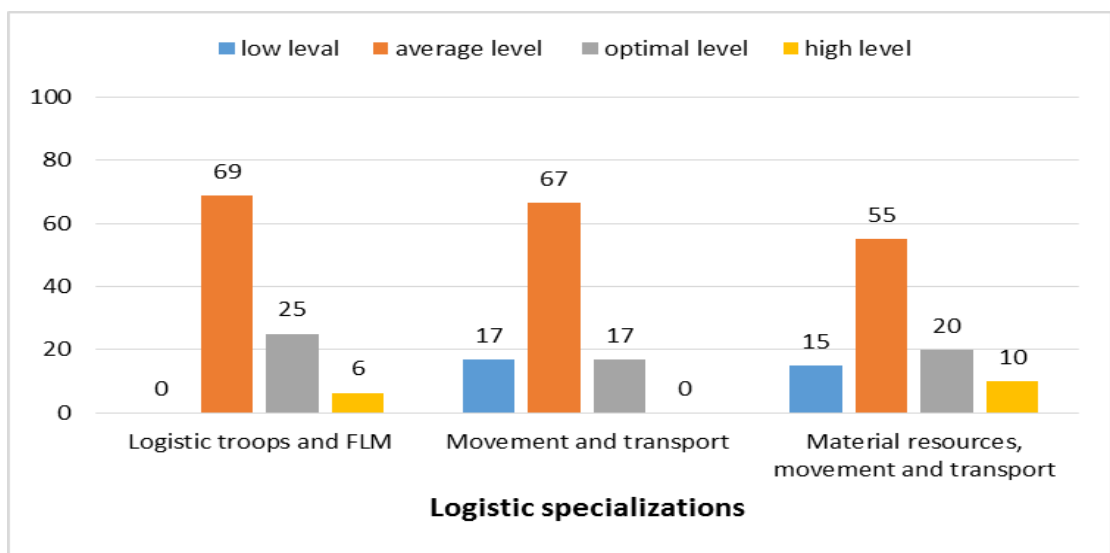

The data from the conducted research of the "result" component show that:

- One trainee from the examined group (5\%) possesses low level and he overestimates the results of his activity.

- One trainee $(5 \%)$ from the examined future non-combatant officers belong to the high level range - the executor strongly underestimates the results of his activity, he's inclined to surplus criticism, disapproval prevails in his evaluation of the other peoples' behavior.

- $90 \%$ of the examined demonstrate an optimal level. For this level it's typical that the executor estimates adequately the results of his activity. He neither underestimates, nor overestimates the result. His evaluations of other people and events are comparatively unprejudiced. His personal development is normally dynamic. The data from the research of the "Result" component are shown on Diagram 3.

Diagram 3: Summarized results of the "Result" component

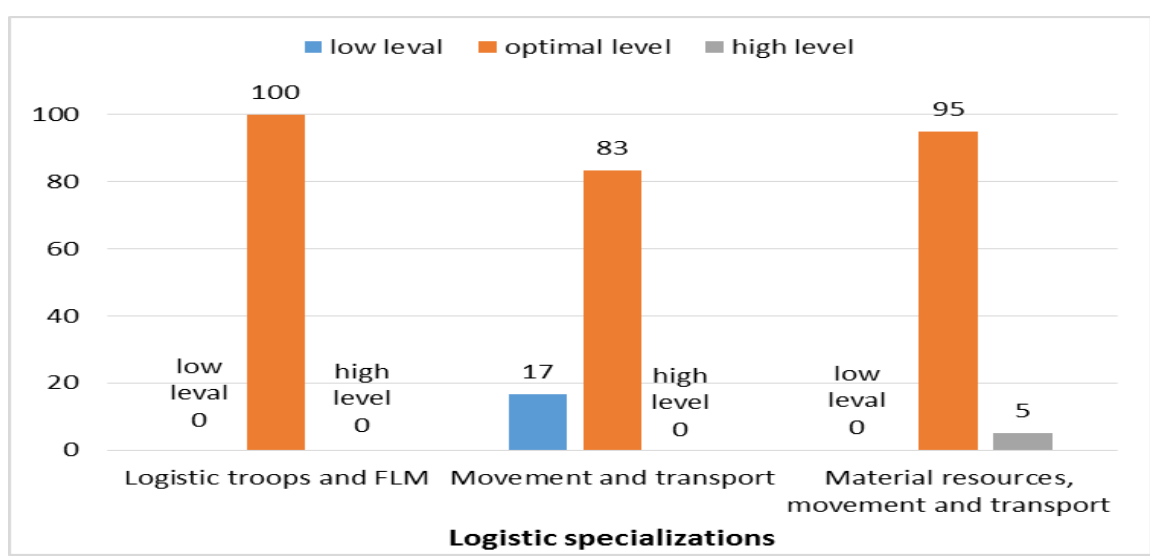

The analysis of the optimal display levels according to the separate components of the structural peculiarities of the management activity shows that the curricula form in the Cadets just $21.5 \%$ of the "instrument" component and $41 \%$ of the "aim" component. On the opposite side is the forming of the "result" component, 
which reaches $90 \%$. The forming of the separate components within the logistic specializations is of big interest to the scientific research. Diagram 4 shows the summarized data about the forming of the optimal levels of display of the components: "Aim", "Instrument" and "result" of the logistic specializations.

Diagram 4: Forming of the optimal levels of display of the separate components of the logistic specializations

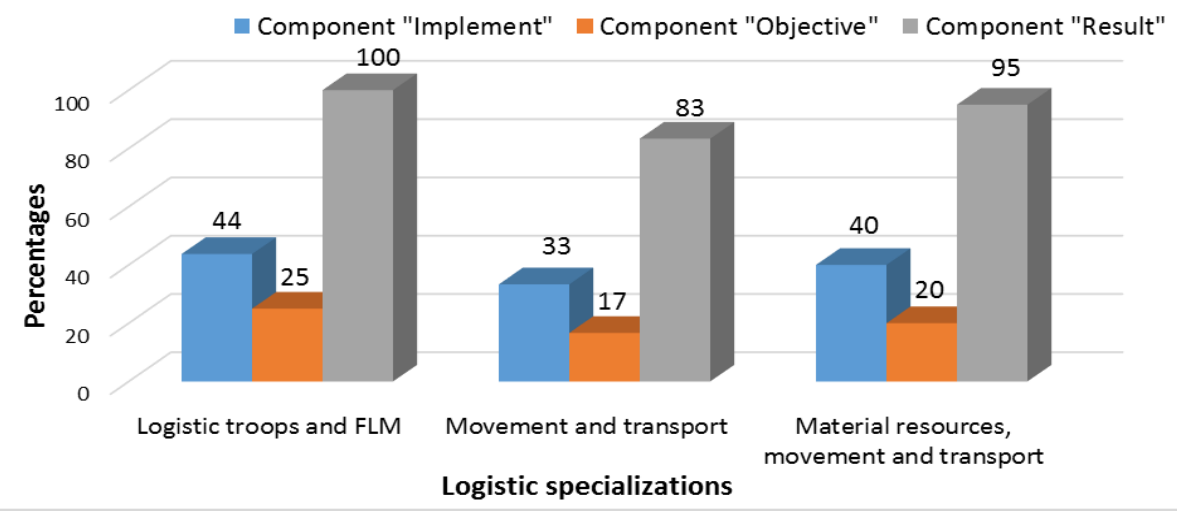

The obtained results of the logistic specializations testify that the common regularity for all the three analyzed specializations are the low values of the optimal levels of the components "Aim" and "Instrument". Out of the three analyzed logistic specializations the best opportunities for establishing a connection between the set goal, the needed resources and the expected result gives the curriculum for the training of the Specialization "Logistic troops and FLM".

\section{MANAGEMENT EFFECTIVENESS}

The methodology of Vasiliy Pougachev was applied during the examination of the management effectiveness. This methodology evaluates not the management properties of a given person, but his practical activity as a leader, his management style from the point of view of his potential effectiveness (Pougachev, 2003, pp. 156-159) (Terziev and Nichev, 2017d, pp. 659-670) (Terziev and Nichev, 2017f, pp. 846-850). The examined person responds to forty questions, choosing from the possible answers "yes" or "no" and for each answer "yes" gets one point, for each "no" - zero points.

In Table 2 are shown the results of the conducted research of the management style of the examined Cadets.

Table 2: Management style in the examined groups

\begin{tabular}{|c|c|c|c|}
\hline $\begin{array}{ll}\begin{array}{l}\text { Management } \\
\text { style }\end{array} & \text { Subgroup } \\
\end{array}$ & SG 1 & SG 2 & $\begin{array}{c}\text { SG } \\
3\end{array}$ \\
\hline Highly effective & 10 & 6 & 9 \\
\hline Medium effective & 6 & - & 11 \\
\hline Less effective & - & - & \\
\hline
\end{tabular}

The percentage of the management styles of the whole examined group is shown on Diagram 5.

Diagram 5: Management style of the examined Cadets in the logistic specializations

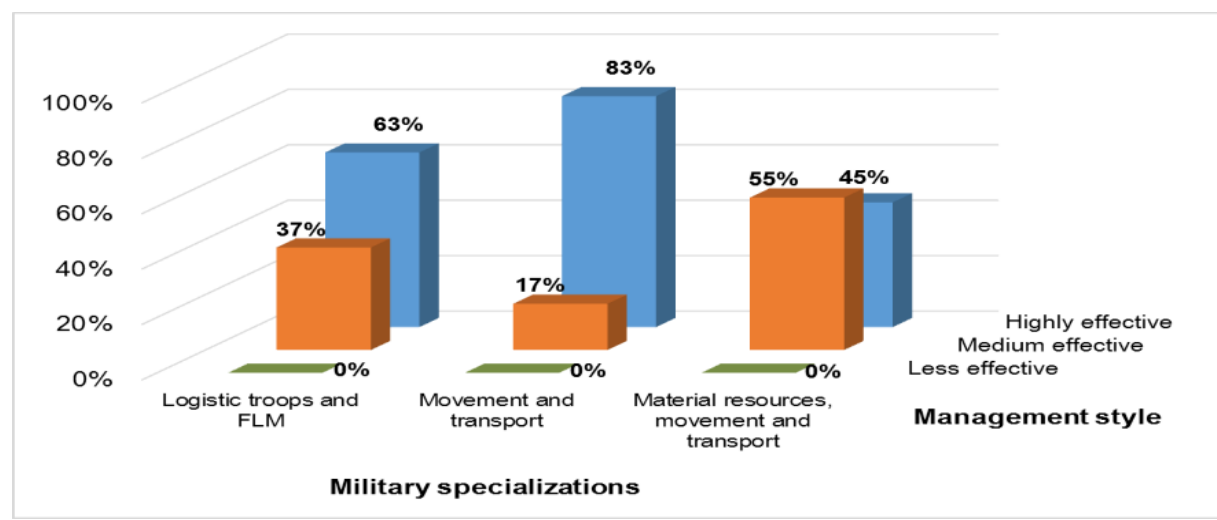


The responses of the cadets display that the curriculum of the specialization "Movement and transport" afford the best opportunities for the development of a highly effective management style. A good indicator is the fact, that there are no students with a less effective management style. The analysis of the management effectiveness shows that the existing system for professional training of the future Logistic officers allows them to form a proper management style.

\section{CONCLUSION}

In conclusion we ought to emphasize that the existing system for professional training gives the opportunity to form a realistic evaluation of the results in the students from the Vasil Levski National Military University. Substantial negative changes are being observed in the development of an adequate choice of means and in the setting of realistic goals in the students from the examined three logistic specializations of the Vasil Levski National Military University. Out of the analyzed specializations, the best opportunities for establishing the connection between the set goal, the needed resources and the expected result are afforded by the curriculum for the training of the specialization "Logistic troops and FLM“.

The development of competences for a management activity in the Cadets during their military professional training is determined mainly by the specified theoretical training of the module "Management and Logistic" according the curricula and the practical training in the military specialized training subjects.

The training of the future non-combatant officers for management activity is an integral part of the military professional training and is conducted during the whole period of their training. One of the directions for improvement of the management effectiveness while taking decisions is to take into consideration the specific of the future military professional activity of the logistic officers. From the point of view of the training of the Cadets for practical activity in the role of leaders and its' potential effectiveness, out of the analyzed logistic specializations the best opportunities are afforded by the training curriculum of the specialization „Movement and transport“.

\section{REFERENCE LIST}

Malkina-Pykh I. (2005). G. Psychosomatics: A handbook of a practical psychologist. Moscow, Publishing house Eksmo

Nichev, N. (2017). Research on the Preparation and Professional Realisation of Newly Appointed Logistics Officers. The 23rd International conference Knowledge-Based Organization, Volume XXIII No 2, pages 399-404

Pougachev V. (2003). Tests, role-playing games, trainings at the personnel command; education for High Schools students, Aspect Press Publisher, Moscow, 2003, pp. 156-159

Terziev, V., Nichev, N. (2017a). Research of the value orientation and structural peculiarities of management activities of cadets in the course of military professional training. Proceedings of the VII International Academic Congress "Fundamental and Applied Studies in EU and CIS Countries" (United Kingdom, Cambridge, England, 26-28 February 2017), Volume VII. Cambridge University Press, pages 646-658

Terziev, V., Nichev, N. (2017b). Analysis of the Environment for Military Educational System Functioning and Its Impact on the Preparation of Cadets for Military Professional Activities in the Republic of Bulgaria. Proceedings of 4th International Conference on Education, Social Sciences and Humanities, 10-12 July 2017, OCERINT, Dubai, UAE, p. 627-630

Terziev, V., Nichev, N. (2017c). Developing the Readiness for the Organizational Activity of the Cadets. Central Bohemia University International Conference Proceedings 2017, Innovations in Science and Education, March 22-24, Published by Central Bohemia University, pages 915-919, http://dx.doi.org/10.12955/cbup.v5.1110, ISSN 1805-997X (Print), ISSN 1805-9961 (Online)

Terziev, V., Nichev, N. (2017d). Research of the motivation for management activities of cadets in the course of their military professional training. Proceedings of the VII International Academic Congress "Fundamental and Applied Studies in EU and CIS Countries" (United Kingdom, Cambridge, England, 
26-28 February 2017), Volume VII. Cambridge University Press, pages 659-670

Terziev, V., Nichev, N. (2017e). Research of the motivation for management activities of cadets in the course of their military professional training. Language and Education, Issue 6 (2). Volume 31. Taylor \& Francis, 2017, Pages 695-706

Terziev, V., Nichev, N. (2017f). Research on the Management Skills and Abilities Acquired in the Military Education System. Central Bohemia University International Conference Proceedings 2017, Innovations in Science and Education, March 22-24, Published by Central Bohemia University, pages 846-850, http://dx.doi.org/10.12955/cbup.v5.1036, ISSN 1805-997X (Print), ISSN 1805-9961 (Online) 